\title{
Retrieval of spatio-temporal distributions of particle parameters from multiwavelength lidar measurements using the linear estimation technique and comparison with AERONET
}

\author{
I. Veselovskii ${ }^{1}$, D. N. Whiteman ${ }^{2}$, M. Korenskiy ${ }^{1}$, A. Kolgotin ${ }^{1}$, O. Dubovik ${ }^{3}$, D. Perez-Ramirez ${ }^{2,4}$, and A. Suvorina ${ }^{1}$ \\ ${ }^{1}$ Physics Instrumentation Center of General Physics Institute, Troitsk, Moscow Region, 142190, Russia \\ ${ }^{2}$ Mesoscale Atmospheric Processes Laboratory, NASA GSFC, Greenbelt, MD 20771, USA \\ ${ }^{3}$ Laboratoire d'Optique Atmospherique, CNRS Universite de Lille 1, Bat P5 Cite scientifique, \\ 59655 Villeneuve d'Ascq Cedex, France \\ ${ }^{4}$ Applied Physics Department, University of Granada, 18071, Granada, Spain \\ Correspondence to: I. Veselovskii (igorv@ pic.troitsk.ru)
}

Received: 10 March 2013 - Published in Atmos. Meas. Tech. Discuss.: 28 March 2013

Revised: 5 September 2013 - Accepted: 6 September 2013 - Published: 16 October 2013

\begin{abstract}
The results of the application of the linear estimation technique to multiwavelength Raman lidar measurements performed during the summer of 2011 in Greenbelt, MD, USA, are presented. We demonstrate that multiwavelength lidars are capable not only of providing vertical profiles of particle properties but also of revealing the spatio-temporal evolution of aerosol features. The nighttime $3 \beta+1 \alpha$ lidar measurements on 21 and 22 July were inverted to spatio-temporal distributions of particle microphysical parameters, such as volume, number density, effective radius and the complex refractive index. The particle volume and number density show strong variation during the night, while the effective radius remains approximately constant. The real part of the refractive index demonstrates a slight decreasing tendency in a region of enhanced extinction coefficient. The linear estimation retrievals are stable and provide time series of particle parameters as a function of height at $4 \mathrm{~min}$ resolution. AERONET observations are compared with multiwavelength lidar retrievals showing good agreement.
\end{abstract}

\section{Introduction}

Multiwavelength (MW) Raman lidar and HSRL (high spectral resolution lidar) are recognized as powerful tools for aerosol characterization. The height-resolved particle backscattering, extinction and depolarization at multiple wavelengths provided by such lidars can be used for aerosol classification (Omar et al., 2009; Burton et al., 2012) and are important parameters in climate modeling (Ganguly et al., 2009; Miller et al., 2011). Another attractive feature of these lidars is the ability to invert the measurements to provide vertical profiles of particle physical properties. During the last decade numerous theoretical and experimental studies have been performed attempting to realize such inversions, and the results obtained look rather promising (Ansmann and Müller, 2005; Böckmann et al., 2005; Veselovskii et al., 2002, 2004, 2009, 2010, 2012; Müller et al., 1999, 2011; Noh et al., 2011). Though the amount of independent observations provided by MW lidar technique is very limited (normally only three backscattering and two extinction coefficients are available, the so called $3 \beta+2 \alpha$ data set), the use of reasonable constraints in the inversions allows the estimation of the particle characteristics. The potential of the method has also been extended due to recent progress in the treatment of desert particles and dust-smoke mixtures (Dubovik et al., 2006; Veselovskii et al., 2010; Tesche et al., 2009; Nishizawa et al., 2011).

To contribute to the study of the Earth's radiation balance, the MW lidar measurements should be performed on a global scale; thus space-borne systems are desirable. The operation of the CALIOP (Cloud-Aerosol LIdar with Orthogonal Polarization) instrument since 2006 has confirmed the potential 
of lidar observations from space for aerosol classification and transport studies (Omar et al., 2009; Winker et al., 2013). The CALIOP instrument possesses just two (532 and $1064 \mathrm{~nm}$ ) backscattering channels in combination with depolarization measurements at $532 \mathrm{~nm}$; thus the next logical step would be to increase the number of the wavelengths and incorporate HSRL channels providing a data set that could support inversions to retrieve particle microphysics. The recent results obtained with the airborne NASA Langley Research Center (LaRC) HSRL system (Hair et al., 2008; Burton et al., 2012) support the importance of this next step, and today the ACE (Aerosols, Clouds, Ecosystems) mission involving a $3 \beta+2 \alpha$ HSRL system is under consideration (http: //dsm.gsfc.nasa.gov/ace).

However before transferring MW lidar technology to space, numerous issues in the analysis of the measurements should be resolved. In particular, the variability of aerosol parameters over the globe should be taken into account: the particles may be of irregular shape, the complex refractive index (CRI) may be size and spectrally dependent and the aerosols may be represented by external or internal mixtures. Thus, to determine realistic uncertainties of the retrieved particle parameters, numerous measurements at different locations are needed, with the results being compared with independent collocated instruments. And finally, given that measurements from space involve large quantities of data and are generally characterized by higher uncertainties than ground-based measurements, the retrieval algorithms used for space-based measurements should be fast enough to manage large volumes of data and tolerant of measurement noise.

The regularization algorithm is used most commonly for inversion of MW measurements (Müller et al., 1999; Veselovskii et al., 2002, 2004), allowing the retrieval of particle size, concentration, CRI, and to some extent the main features of the particle size distribution (PSD). However, regularization methods are quite time consuming, so it is attractive to test other inversion techniques as possible candidates for operational algorithms for space-based data. One of the possible approaches to the inversion is based on the expansion of the PSD in terms of the measurement kernels (Twomey, 1977; Thomason and Osborn, 1992; Donovan and Carswell, 1997; Veselovskii et al., 2012; De Graaf et al., 2013). The particle bulk properties in the frame of this approach are represented by a linear combination of the input optical data, so here and below we will refer to it as "linear estimation". The regularization and the linear estimation (LE) techniques are characterized by similar uncertainties (Veselovskii et al., 2012), but the LE technique is faster because there is no need to solve the system of linear equations for different values of predefined regularization parameters (Veselovskii et al., 2002, 2012). Application of this approach to measurements performed in Turkey (Veselovskii et al., 2012) has demonstrated the stability of the retrieval and the possibility of obtaining the spatio-temporal values of particle parameters.
The most practical configuration of backscatter-Raman lidar is based on a tripled Nd:YAG laser, supporting the measurement of three backscattering $\left(\beta_{355,532,1064}\right)$ and two extinction $\left(\alpha_{355,532}\right)$ coefficients. One of the main issues in processing such Raman lidar measurements is the calculation of the particle extinction coefficient, because it is based on numerical differentiation of a weak nitrogen Raman signal (Ansmann et al., 1992; Whiteman, 1999). This problem is especially critical for the calculation of the extinction coefficient at $532 \mathrm{~nm}\left(\alpha_{532}\right)$, where both the Raman signal and the aerosol extinction coefficient are normally lower than at $355 \mathrm{~nm}$. As a result $\alpha_{532}$ is characterized by higher errors, especially for daytime measurements. Furthermore, a recent sensitivity study (Perez-Ramirez et al., 2013) demonstrates that retrieved particle parameters are in general much more sensitive to errors in the input extinction data than the backscattering data. Therefore, in many situations it could be desirable to exclude $\alpha_{532}$ from the input data. Such a reduced $3 \beta+1 \alpha$ data set is not sufficient to reproduce the details of the PSD, but the particle bulk properties in most cases still can be estimated. The first results of such a data reduction study demonstrate that at least for a PSD with prevailing fine mode the inversion of the full $(3 \beta+2 \alpha)$ and reduced $(3 \beta+1 \alpha)$ data sets leads to similar results (Veselovskii et al., 2012).

In this paper we extend that previous study by performing simulations and applying the regularization and LE approaches to the full and reduced data sets of extended lidar measurements performed with the MW Raman lidar at NASA Goddard Space Flight Center (GSFC) in Greenbelt, MD, during the summer of 2011. To evaluate the technique, the lidar retrievals are compared with the results provided by AERONET (Holben et al., 1998).

\section{Approach to retrieval}

The aerosol extinction $(\alpha)$ and backscattering coefficients $(\beta)$ are related to the particle size distribution (PSD) $\frac{\mathrm{d} V(r)}{\mathrm{d} r}$ via integral equations as follows:

$g_{p}=\int_{r_{\min }}^{r_{\max }} K_{p}(m, r) \frac{\mathrm{d} V(r)}{\mathrm{d} r} \mathrm{~d} r p=1, \ldots, N$.

The index $p$ represents the type of optical data $(\alpha, \beta)$ and wavelengths; $K_{p}(m, r)$ are the volume kernels (VK) depending on the complex refractive index (CRI) $m=m_{\mathrm{R}}-i m_{\mathrm{I}}$ and particle radius $r \in\left[r_{\min }, r_{\max }\right]$.

A detailed description of the linear estimation approach is given in Veselovskii et al. (2012). Equation (1) can be rewritten in the matrix-vector form. The vector of input optical data $g$ (aerosol extinction and backscattering coefficients) is related to the volume size distribution $\boldsymbol{v}$ as

$\mathbf{K} v=g$, 
where $\mathbf{K}$ is the matrix containing discretized measurement kernels as columns.

Any particle bulk property $p$ (for example, volume, surface or number density) can be estimated as

$p=\mathbf{P} \boldsymbol{v}=\mathbf{P} \mathbf{K}^{T}\left(\mathbf{K K}^{T}\right)^{-1} \boldsymbol{g}$.

Here $\mathbf{P}$ is a matrix containing the weight coefficients for different integral properties as rows. For example for volume $(i=1), P_{1 k}=1$; for surface (i=2), $P_{2 k}=\frac{3}{r_{k}}$; and for number density $(i=3), P_{3 k}=\frac{3}{4 \pi r_{k}^{3}}$. It should be mentioned that when retrieving $p$, we consider only projections of the characteristics of $p$ on the measured set $g$ and ignore the residual $\boldsymbol{p}_{\perp}$ that cannot be measured directly with the available set of observations $\boldsymbol{g}$ (the so-called null space). Our previous results demonstrate that the existence of a null space does not present a serious limitation to the LE technique for typical atmospheric aerosols (Veselovskii et al., 2012).

The inverse problem in our formulation is underdetermined: the set of lidar measurements within a single atmospheric layer is limited - typically only 5 observations. This number of measurements is not sufficient to uniquely describe the properties of the aerosol; therefore, we use an intermediate approach. We perform inversions using a reasonable set of constraints and generate a family of solutions. Specifically, we consider a set of inversion windows $\left[r_{\min }\right.$, $\left.r_{\max }\right]$ and complex refractive indices $m=m_{\mathrm{R}}-i m_{\mathrm{I}}$ from the corresponding intervals. The ranges of allowed values for the parameters can be considered as a priori constraints. Although those constraints do not provide a unique solution, they help to significantly reduce the number of solution family members.

Whatever approach we use for inversion (regularization or linear estimation) the key point is identifying a group of solutions which, after averaging, can provide a realistic estimation of the particle parameters. Such identification can be done by considering the discrepancy $\rho$ defined as the difference between the input optical data $g$ and the optical data $\tilde{g}_{p}(m)$ calculated from the solution obtained for specific values of the input parameters. In the linear estimation technique, we choose one optical datum $g_{p}$ and estimate it from the rest of the $N-1$ data using Eq. (3), as suggested in De Graaf et al. (2013). By doing so for each optical datum, we obtain estimates of $\tilde{g}_{p}(m)$, which we compare with the observations $g_{p}$. The discrepancy $\rho$ is then calculated as

$\rho=\sqrt{\frac{\sum_{p}^{N}\left(g_{p}-\tilde{g}_{p}(m)\right)^{2}}{N} .}$

Thus, the discrepancy can quantify inconsistency in the input optical data. A high discrepancy means that no appropriate particle parameters were found since the solution obtained does not generate optical data close to the observations $g$ and normally this points to problems in the measurements.
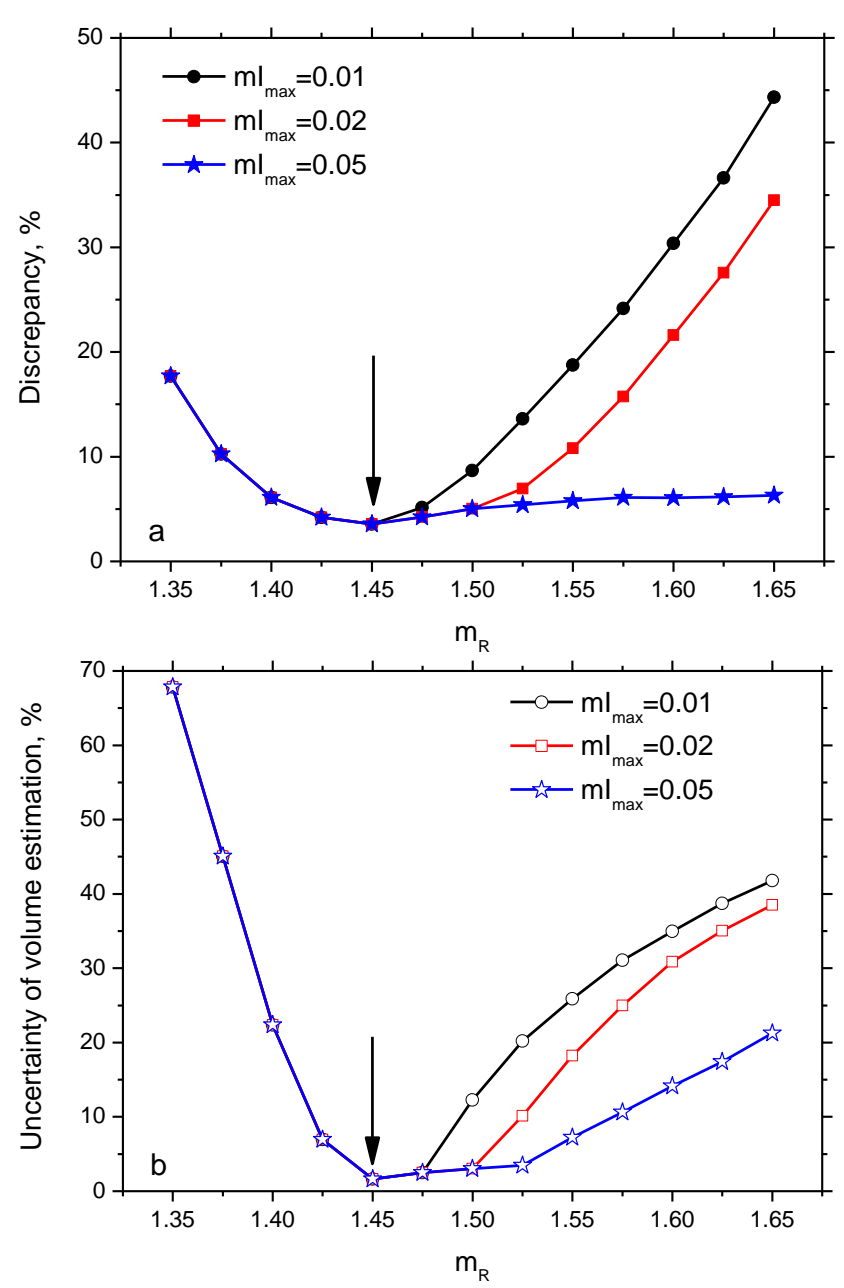

Fig. 1. (a) Discrepancy and (b) uncertainty of volume estimation as a function of assumed values of the real part of the refractive index for different ranges of considered values of the imaginary part with maximum values $m_{\mathrm{I}}=0.01,0.02,0.05$. The simulation was performed for a log-normal PSD with modal radius $r_{0}=0.15 \mu \mathrm{m}$ and dispersion $\ln \sigma=0.4$. The arrow shows the real part of the refractive index $m_{\mathrm{R}}=1.45$ for the synthetic data.

As pointed out in our previous publication (Veselovskii et al., 2012), the high sensitivity of $g$ to $m$ allows the estimation of particle refractive index by calculating $\Delta g_{p}=\tilde{g}_{p}-g_{p}$ for different assumed values of $m$ and by searching for the minimum of the discrepancy. We should recall, however, that the complex refractive index in our approach is assumed to be spectrally independent. The estimation of the real part of the refractive index from the minimization of $\rho$ in Eq. (4) for the $3 \beta+2 \alpha$ data set using the linear estimation approach is illustrated by Fig. 1 where the discrepancy $\rho$ and the uncertainty of the volume estimation $\varepsilon_{V}$ are given for different assumptions of $m_{\mathrm{R}}$. Synthetic input data were generated assuming a log-normal distribution of particle number density $\frac{\mathrm{d} n(r)}{\mathrm{d} \ln r}$ with modal radius $0.15 \mu \mathrm{m}$ and variance 0.4 ; the model refractive index is $m=1.45-i 0.005$. The behavior of $\rho\left(m_{\mathrm{R}}\right)$ 
depends on the range of parameters considered; in particular it depends on the range of the imaginary part considered $[0$, $\left.m_{\mathrm{I}, \max }\right]$. The computations in Fig. 1 were performed for values $m_{\mathrm{I}, \max }=0.01,0.02,0.05$. For an accurate estimation of $m_{\mathrm{R}}$ a global minimum near the model value $m_{\mathrm{R}}$ is needed. Figure 1a demonstrates that, for $m_{\mathrm{I}, \max }=0.01, m_{\mathrm{R}}(\rho)$ has such a minimum at a value of approximately 1.45 , so that the discrepancy rises for $m_{\mathrm{R}}$ above and below 1.45. However for larger $m_{\mathrm{I}, \max }$ the minimum becomes wider, meaning that the accuracy of the estimation of $m_{\mathrm{R}}$ decreases, and for $m_{\mathrm{I}, \max }=0.05$ it is practically flat from 1.45 to 1.65 , so estimates of $m_{\mathrm{R}}$ in this range will have considerable uncertainty. Figure $1 \mathrm{~b}$ shows the corresponding uncertainties of the volume estimation determined as $\varepsilon_{V}=\frac{\left|V_{\bmod }-V_{\text {retr }}\right|}{V_{\text {mod }}}$, where $V_{\text {mod }}$ and $V_{\text {retr }}$ are model and retrieved values of volume. It is interesting that, even though for the high values of $m_{\mathrm{I}, \max }$ the real part of CRI cannot be determined with accuracy, the uncertainty of the volume estimation $\varepsilon_{V}$ made using incorrect values of $m_{\mathrm{R}}$ does not increase significantly, which is in agreement also with the results presented in Perez-Ramirez et al. (2013). From Fig. $1 \mathrm{~b}$ we can conclude that $\varepsilon_{V} \approx 20 \%$ when we choose $m_{\mathrm{R}}=1.65$ instead of 1.45 . The same is true for the rest of the parameters such as number, surface density and effective radius. So finally, the increase of the range of the values of $m_{\mathrm{I}}$ considered degrades the accuracy of the estimation of $m_{\mathrm{R}}$, even though the other bulk properties can still be retrieved. Similar plots of $m_{\mathrm{I}}(\rho)$ can be provided to illustrate the estimation of the imaginary part of the refractive index. The corresponding simulation leads to the same conclusion: a reasonable estimation of $m_{\mathrm{I}}$ can only be made if preliminary information about the range of $m_{\mathrm{I}}$ variation is available.

The results presented in Fig. 1 were obtained assuming that the simulated measurements contain no errors. The errors in the simulated input data will modify $m_{\mathrm{R}}(\rho)$, thus degrading the accuracy of the estimation of $m_{\mathrm{R}}$. To analyze this effect, errors were introduced in the synthetic input data in a random way in the range of $0-10 \%$. Figure 2 shows $m_{\mathrm{R}}(\rho)$ plots for ten realizations following such a procedure assuming $m_{\mathrm{I}, \max }=0.01 . m_{\mathrm{R}}(\rho)$ varies from realization to realization; still the uncertainty of the estimation of $m_{\mathrm{R}}$ is below \pm 0.05 . The corresponding uncertainty of the volume density estimation does not exceed $20 \%$. These plots illustrate the possibility of estimating the real part of the refractive index from the measurements if we reasonably limit the range of values of $m_{\mathrm{I}}$ considered.

\section{Numerical simulation}

Numerical simulations were performed to estimate the uncertainties of the inversion of the complete $3 \beta+2 \alpha$ and reduced $3 \beta+1 \alpha$ (where extinction at $532 \mathrm{~nm}$ is removed) data sets using regularization and LE approaches. Synthetic input optical

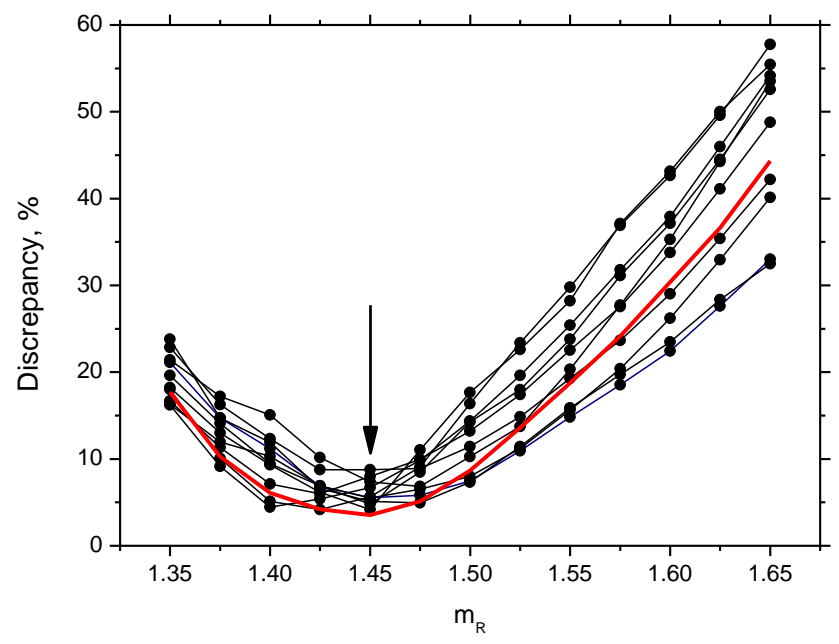

Fig. 2. Influence of random uncertainties in the input data on the discrepancy $\rho\left(m_{\mathrm{R}}\right)$. The simulation was performed for the same parameters as in Fig. 1 and the maximum value of $m_{\mathrm{I}}$ was 0.01 . The results are presented for ten realizations with random errors in the range of $0-10 \%$. The solid red line represents $\rho\left(m_{\mathrm{R}}\right)$ in the absence of input errors; the arrow shows the model value of the real part of the refractive index $m_{\mathrm{R}}=1.45$.

data were generated for a bimodal particle size distribution:

$$
\frac{\mathrm{d} n(r)}{\mathrm{d} \ln (r)}=\sum_{i=\mathrm{f}, \mathrm{c}} \frac{N_{\mathrm{I}}}{(2 \pi)^{1 / 2} \ln \sigma_{i}} \exp \left[-\frac{\left(\ln r-\ln r_{i}\right)^{2}}{2\left(\ln \sigma_{i}\right)^{2}}\right] .
$$

Here $N_{\mathrm{f}, \mathrm{c}}$ is particle number density in the fine (f) and the coarse (c) mode. Each mode is represented by a lognormal distribution with modal radius $r_{\mathrm{f}, \mathrm{c}}$ and dispersion $\ln \sigma_{\mathrm{f}, \mathrm{c}}$. The simulations were intended to support the analysis of our measurements at NASA GSFC. From collocated, multi-year AERONET measurements we can conclude that aerosols in the summer season in the Greenbelt, MD area typically are characterized by a size distribution where the fine mode dominates (Dubovik et al., 2002). Thus, when performing simulations, the following scenario was considered: the ratio of the particle number densities is range independent. The value of $r_{\mathrm{f}}$ changes with range from 0.1 to $0.3 \mu \mathrm{m}$, while $r_{\mathrm{c}}=1 \mu \mathrm{m}$ is fixed. As a result the effective radius varies with range from 0.19 to $0.53 \mu \mathrm{m}$ as shown in Fig. 3. The volume density varies from 15 to $300 \mu \mathrm{m}^{3} \mathrm{~cm}^{-3}$, and CRI for both modes has a range-independent value of $m=1.45-i 0.005$. The retrievals were performed using both the LE and regularization techniques to compare their performance. The "search space" of the parameters considered was $0.05 \mu \mathrm{m}<r<10 \mu \mathrm{m} ; 1.35<m_{\mathrm{R}}<1.65$; and $0<m_{\mathrm{I}}<0.015$.

The results of $3 \beta+2 \alpha$ and $3 \beta+1 \alpha$ data inversion are shown in Fig. 3. The input data are assumed to be free of errors, but uncertainties in retrievals still exist due to the unknown value of the CRI, due to the approximation of the PSD with the set of base functions (in the case of regularization) 

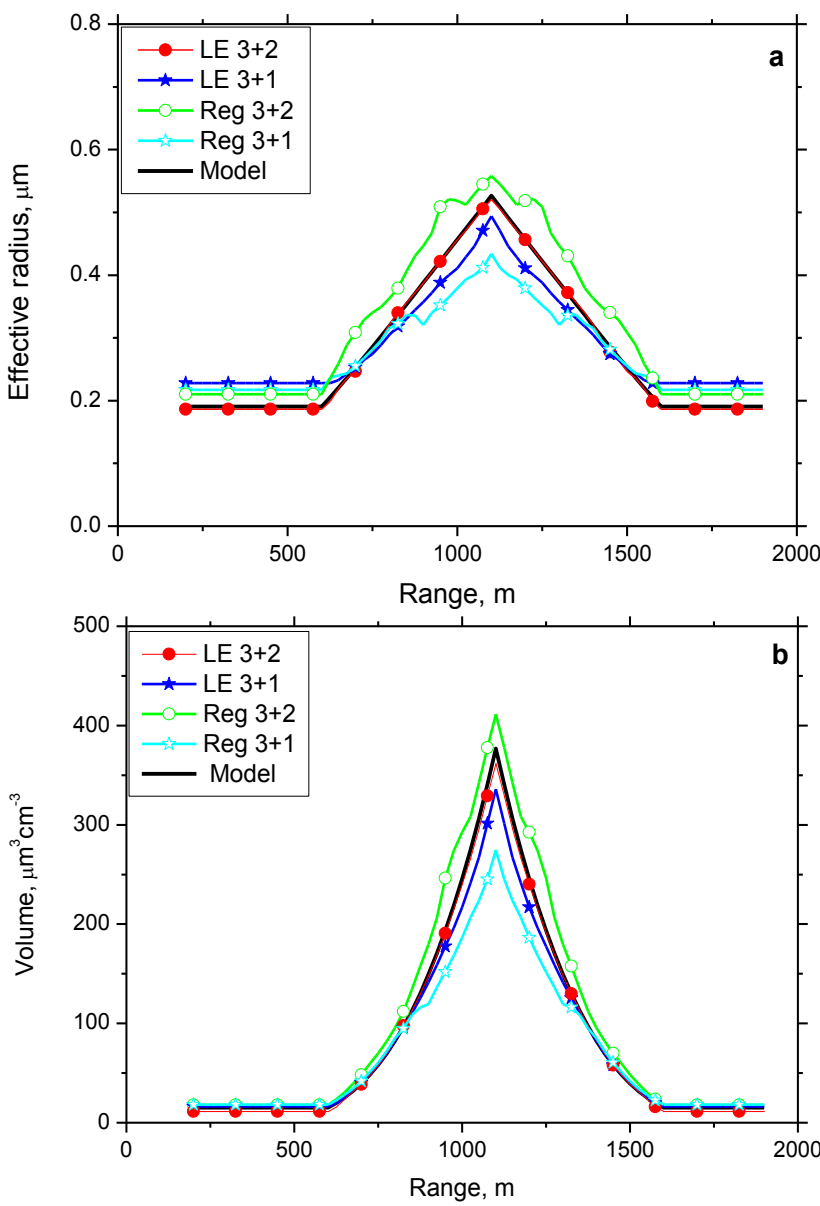

Fig. 3. Retrieval of range-dependent (a) effective radius and (b) volume density from synthetic optical data. Results are given for regularization and LE techniques applied to $3 \beta+2 \alpha$ and $3 \beta+1 \alpha$ measurements. The black solid line shows the model particle parameters. The input optical data are free of errors.

and due to the existence of a null space (in the case of LE). Retrievals of effective radius and volume performed with the LE approach using $3 \beta+2 \alpha$ measurements coincide well with the model values. The agreement with the model is still good when extinction at $532 \mathrm{~nm}$ is excluded from the measurements; however for model values $r_{\text {eff }}<0.2 \mu \mathrm{m}$ the retrieved effective radius is overestimated. The regularization retrieval is characterized by higher uncertainties: for $3 \beta+2 \alpha, r_{\text {eff }}$ and $V$ are slightly overestimated, while for $3 \beta+1 \alpha$ these parameters are underestimated.

To evaluate the effect of noise in the optical data on the retrieved values, random errors in the range $0-10 \%$ were introduced into the simulated data sets. The inversion procedure was repeated 20 times and the results are summarized in Table 1, showing the uncertainties of effective radius $\left(\varepsilon_{\text {reff }}\right)$, volume density $\left(\varepsilon_{V}\right)$ and the real part of CRI estimation for several chosen values of model effective radius. For $90 \%$ of the realizations, the uncertainty of the estimation of the parti- cle parameters was below the values listed in the table. From the results of these simulations, we can conclude that for a PSD with a dominant fine mode, the LE approach has some advantages over regularization. For example, the range of errors in $r_{\text {eff }}$ using the LE approach and $3 \beta+2 \alpha$ input data is $10-20 \%$, while, using the same data, the range of errors for the regularization approach is $30-35 \%$. When considering the $3 \beta+1 \alpha$ data set and retrieval of $r_{\text {eff }}$, there is again an increase in errors when using regularization versus linear estimation. Careful study of the table indicates that for the model aerosol distribution studied here with fine mode predominance the LE approach consistently resulted in lower errors when compared with regularization. It is interesting that for regularization the data reduction at small radii leads to a decrease of $\varepsilon_{\text {reff. }}$ The behavior of $\varepsilon_{V}$ is similar. These results can be due to the higher sensitivity of the retrievals to the input extinction versus backscattering as previously mentioned (Perez-Ramirez et al., 2013).

Data reduction (i.e. excluding $\alpha_{532}$ ) modifies $\varepsilon_{\mathrm{mR}}$ for the regularization and LE techniques in different ways. Using the regularization technique and $3 \beta+2 \alpha$, the uncertainty of the estimation of $m_{\mathrm{R}}$ does not exceed 0.05 for all radii, but the exclusion of $\alpha_{532}$ from the input data causes $\varepsilon_{\mathrm{mR}}$ to increase to 0.1 for $r_{\text {eff }}>0.4 \mu \mathrm{m}$. For the LE technique with the same input data, the behavior is different: data reduction decreases $\varepsilon_{\mathrm{mR}}$ for all radii, in particular for small radii where it decreases from 0.07 to 0.05 .

In discussing the effect of data reduction we should point out that, in principle, the uncertainties of $3 \beta+1 \alpha$ inversion can be lower than $3 \beta+2 \alpha$. As we have already mentioned, the retrievals are more sensitive to the errors in extinction than in backscattering (Perez-Ramirez et al., 2013); thus adding an additional extinction value to the input data set is a trade between new information available and the uncertainty of retrieval induced by the errors in this additional extinction. On the other hand, the use of $3 \beta+2 \alpha$ input data is advantageous if details of the PSD, such as the contributions of the fine and the coarse mode to the total volume, are needed.

We should emphasize also that the simulation performed here is rather simplified. For example, the effects of a spectrally and size-dependent refractive index are not considered. The results presented here compare the sensitivity of two techniques to input noise for different particle radii and data sets, but assessment of the absolute accuracy of the retrieval is outside of the scope of the current activity.

\section{Results of the measurements}

The measurements were performed at NASA GSFC in Greenbelt, MD, during July-August of 2011. The multiwavelength Mie-Raman lidar at NASA GSFC is based on a Continuum 9050 laser with $50 \mathrm{~Hz}$ repetition rate. The output powers at $\lambda=355,532$ and $1064 \mathrm{~nm}$ are approximately 15 , 
Table 1. Uncertainties of effective radius $\left(\varepsilon_{\text {reff }}\right)$, volume density $\left(\varepsilon_{V}\right)$ and the real part of CRI $\left(\varepsilon_{\mathrm{mR}}\right)$ retrieval with regularization and LE approaches from $3 \beta+2 \alpha / 3 \beta+1 \alpha$ data sets.

\begin{tabular}{|c|c|c|c|c|c|c|}
\hline \multicolumn{3}{|c|}{ Model $r_{\mathrm{eff}}, \mu \mathrm{m}$} & 0.2 & 0.3 & 0.4 & 0.5 \\
\hline \multirow{6}{*}{ Errors } & \multirow{3}{*}{ LE } & $\varepsilon_{\text {reff }}, \%$ & $20 / 30$ & $20 / 15$ & $10 / 15$ & $10 / 15$ \\
\hline & & $\varepsilon_{V}, \%$ & $30 / 25$ & $20 / 10$ & $10 / 15$ & $15 / 20$ \\
\hline & & $m_{\mathrm{R}}$ & $0.07 / 0.05$ & $0.04 / 0.03$ & $0.03 / 0.03$ & $0.03 / 0.03$ \\
\hline & \multirow{3}{*}{ Regular. } & $\varepsilon_{\text {reff }}, \%$ & $30 / 20$ & $35 / 30$ & $35 / 35$ & $30 / 40$ \\
\hline & & $\varepsilon_{V}, \%$ & $35 / 30$ & $40 / 25$ & $45 / 35$ & $35 / 40$ \\
\hline & & $m_{\mathrm{R}}$ & $0.05 / 0.05$ & $0.04 / 0.07$ & $0.03 / 0.1$ & $0.03 / 0.11$ \\
\hline
\end{tabular}

7 and $12 \mathrm{~W}$, respectively. The backscattered light is collected by a $40 \mathrm{~cm}$-aperture Schmidt-Cassegrain telescope operated vertically at $0.5 \mathrm{mrad}$ field of view. The system is capable of detecting three backscattered signals at the laser wavelengths and two nitrogen Raman signals at $\lambda_{\mathrm{R}}=387$ and $607 \mathrm{~nm}$. The outputs of the detectors are recorded at $7.5 \mathrm{~m}$ range resolution using Licel transient recorders that incorporate both analog and photon-counting electronics. The full geometrical overlap of the laser beam and the telescope FOV is achieved at $\sim 1000 \mathrm{~m}$, which determines the lower limit of the full set of our $3 \beta+2 \alpha$ measurements due to the difficulty of calculating aerosol extinction in the overlap region.

For each profile, 6000 laser pulses were accumulated so the temporal resolution of the measurements was $2 \mathrm{~min}$. The measurements were performed both in day- and nighttime, but the full set of the measurements containing both backscatter and Raman signals could be acquired only in the nighttime. So in this paper, only the results of the nighttime measurements are presented. The vertical profiles of the temperature and relative humidity were available from radiosondes launched at the Howard University research campus in Beltsville, MD, approximately $10 \mathrm{~km}$ away from GSFC.

As shown in a previous section, for the retrieval of bulk particle properties, the number of input optical data can be reduced while maintaining good performance of the retrieval at least for the case when the fine mode dominates in the PSD as is the typical situation for the summer season in Maryland (Dubovik et al., 2002). Thus, instead of using the full $3 \beta+2 \alpha$ measurements, the reduced set of $3 \beta+1 \alpha$ where extinction at $532 \mathrm{~nm}$ is excluded was used. This data reduction significantly simplifies data processing, because $\alpha_{532}$ determined from Raman nitrogen scattering with 2 min temporal resolution is characterized by significant uncertainty. But even for calculations of particle extinction at $355 \mathrm{~nm}$ from the Raman nitrogen signal, the vertical resolution was degraded to improve the signal-to-noise ratio. In our calculations, the vertical resolution varied with height from $75 \mathrm{~m}$ (at $1000 \mathrm{~m}$ ) up to $200 \mathrm{~m}$ (at $5000 \mathrm{~m}$ ). The lidar signals were also smoothed in the temporal domain by using a sliding average of 3 profiles. The effective temporal resolution of the result was, therefore, approximately $4 \mathrm{~min}$. The particle depolarization at $355 \mathrm{~nm}$
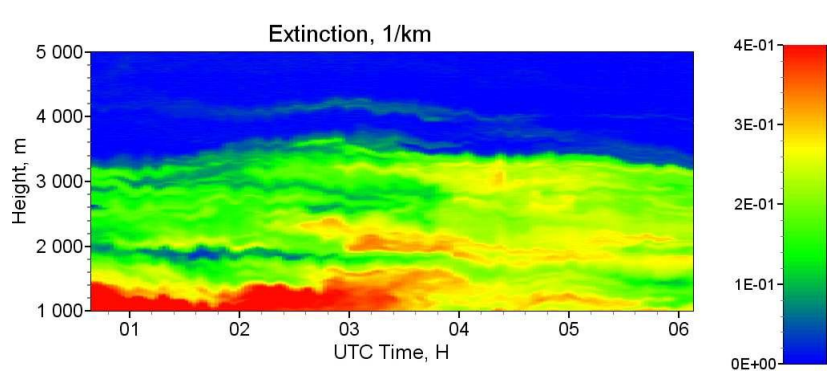

Fig. 4. Aerosol extinction at $355 \mathrm{~nm}$ on the night of 20-21 July calculated using the Klett method.

in our measurements was below $5 \%$, indicating nearly spherical particles; thus all retrievals presented in this section were obtained from the $3 \beta+1 \alpha$ measurements with the LE algorithm that used kernel functions for spherical particles.

To illustrate the application of the linear estimation technique for the retrieval of a time series of particle parameters, we have chosen measurements performed during the nights of 20-21 and 21-22 July 2011. For these nights, five-day backward trajectories of the airmasses affecting the study area were calculated by the HYSPLIT-4 (Draxler and Rolph, 2013) model. On the night of 20-21 July, at 500 and $1500 \mathrm{~m}$ the airmasses had their origins over the Midwest of the United States and followed a path through the areas of the Great Lakes, acquiring pollution-generated aerosols as they traveled. On the night of 21-22 July, the origin of the airmasses shifted to the southern United States and the airmasses also followed a path over polluted areas near the Great Lakes.

\section{$4.1 \quad 20-21$ July measurements}

The structure of the PBL during the night of 20-21 July is illustrated by Fig. 4. The particle extinction at $355 \mathrm{~nm}$ is calculated by the Klett method (Klett, 1985) assuming the lidar ratio to be $70 \mathrm{sr}$, which was the average value of the lidar ratio derived from the Raman measurements. We should emphasize that the Klett profiles are not used in retrievals and the only reason for showing these is to illustrate the fine structure of the aerosol layers, because the height resolution of 

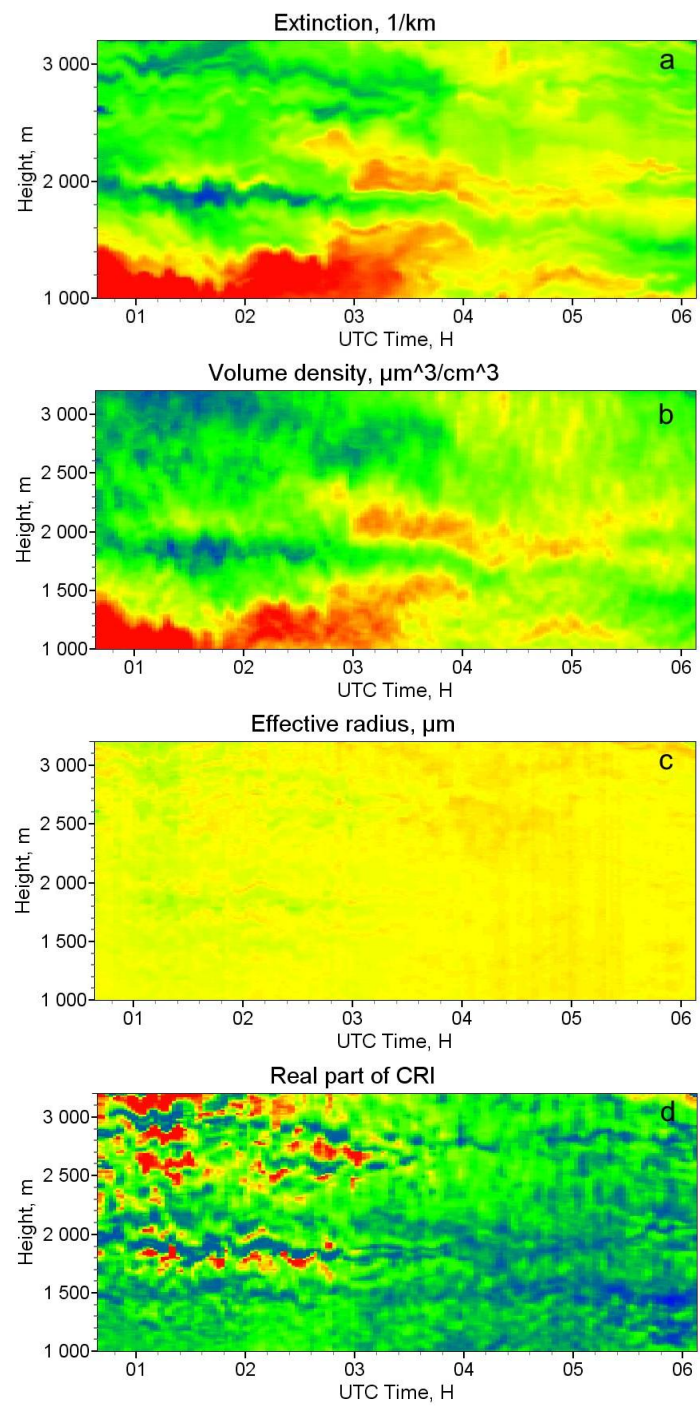

Fig. 5. Spatio-temporal distribution of (a) particle extinction at $355 \mathrm{~nm}$ calculated from the nitrogen Raman signal together with (b) particle volume, (c) effective radius and (d) the real part of the complex refractive index on 21 July 2011.

the Klett calculation is $7.5 \mathrm{~m}$ while the Raman technique requires more spatial and temporal averaging of the data. The top of the PBL is below $3500 \mathrm{~m}$, although weak aerosol layers are observed up to approximately $4000 \mathrm{~m}$. However, the optical density of these layers is too low for reliable computations of particle extinction and backscattering by the Raman method, so we limit the height range where the optical data are inverted to particle properties to altitudes less than $3200 \mathrm{~m}$.

The spatio-temporal distribution of particle extinction at $355 \mathrm{~nm}$ calculated from the nitrogen Raman signal is shown in Fig. 5a. In the period from 00:40 UTC to 03:00 UTC a region of high aerosol loading, with extinction coefficient up to $0.4 \mathrm{~km}^{-1}$, extended up to $\sim 1400 \mathrm{~m}$. Above that height $\alpha_{355}$
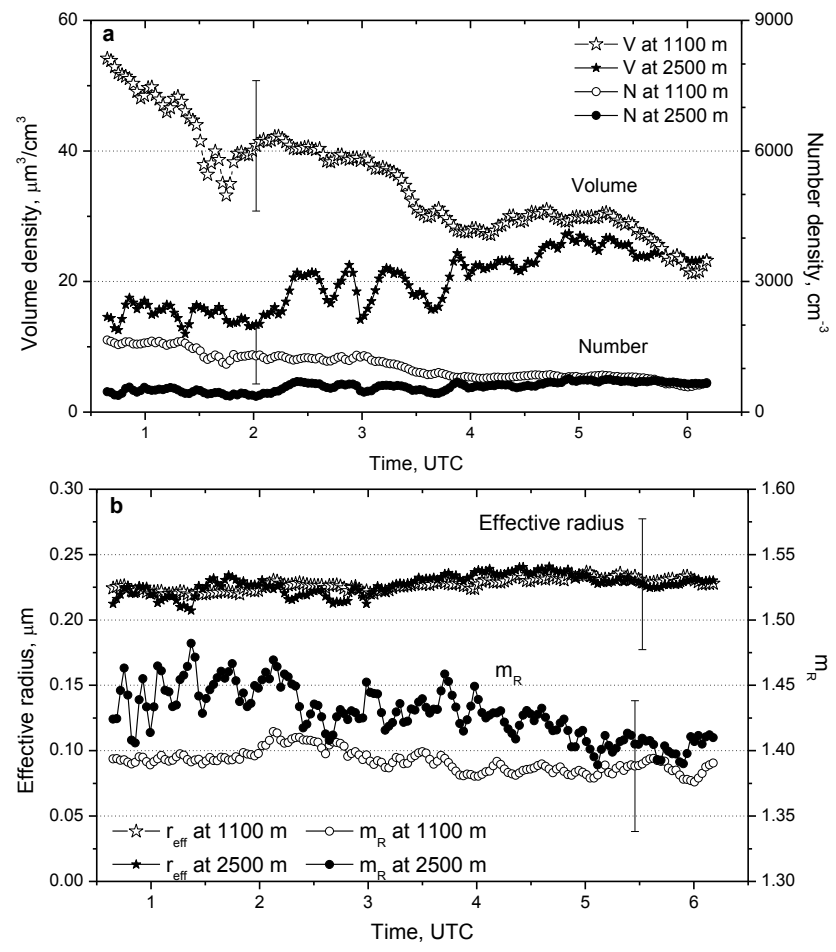

Fig. 6. Time series of (a) particle volume and number density together with (b) effective radius and real part of the refractive index obtained from lidar measurements on 21 July 2011. The lidarderived parameters are averaged in layers of $200 \mathrm{~m}$ thickness and centered at $1100 \mathrm{~m}$ (open symbols) and $2500 \mathrm{~m}$ (solid symbols).

dropped to $\sim 0.15 \mathrm{~km}^{-1}$. After 03:00 UTC a second layer appeared at $2000 \mathrm{~m}$ and aerosols became distributed more uniformly through the PBL. The retrieved spatio-temporal distributions of the particle bulk parameters, such as volume density, effective radius and the real part of the refractive index, are shown in Fig. 5b-d. The particle volume follows the extinction coefficient, meaning that the effective radius and the refractive index did not vary significantly. The real part of the refractive index is quite oscillatory in the region characterized by lower particle extinction (above $2000 \mathrm{~m}$ during 00:40-03:00 UTC), likely due to the propagation of errors in the optical data, but after 03:00 UTC, when aerosols are distributed more uniformly through the PBL, $m_{\mathrm{R}}$ becomes more stable and drops to approximately 1.4.

To quantify variations of the retrieved parameters, Fig. 6 shows the time series of the volume, number density, effective radius and the real part of the refractive index in two layers of $200 \mathrm{~m}$ thickness centered at 1100 and $2500 \mathrm{~m}$ where, inside of these layers, the parameters are averaged. The volume density at $1100 \mathrm{~m}$ drops from approximately $50 \mu \mathrm{m}^{3} \mathrm{~cm}^{-3}$ at 00:40 UTC to $\sim 30 \mu \mathrm{m}^{3} \mathrm{~cm}^{-3}$ at 04:00 UTC, while $V$ at $2500 \mathrm{~m}$ rises and after 04:00 UTC the volume densities in both layers have similar values. The number densities behave in a similar manner. Effective radii for both layers are also similar and rise slightly with time from 0.22 

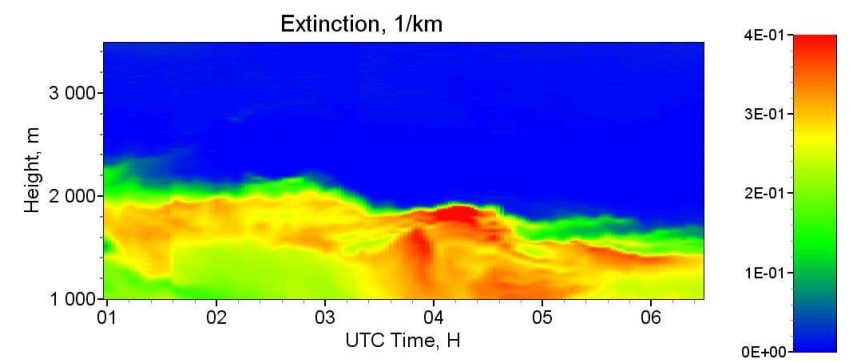

Fig. 7. Aerosol extinction at $355 \mathrm{~nm}$ on the night of 21-22 July calculated using the Klett method. The assumed lidar ratio is $70 \mathrm{sr}$.

to $0.24 \mu \mathrm{m}$. The real part of the complex refractive index (CRI) at $2500 \mathrm{~m}$ is larger than that in the $1100 \mathrm{~m}$ layer at 01:00 UTC, but by 05:00 UTC $m_{\mathrm{R}}$ in both layers is approximately 1.4. We estimate the uncertainties of the effective radius and volume retrieval to be below 30 and $25 \%$, respectively. The uncertainty of the real part of the CRI is \pm 0.05 . Meanwhile the uncertainty of the relative change in the parameters should be lower, because the absolute uncertainty includes biases introduced by the existence of a "null space" and by the choice of the "search space" for the particle radii and CRI. These latter biases appear to have influenced all retrievals similarly since we do not see large changes in the retrieved radii and CRI.

The retrieved imaginary part of the refractive index is about 0.006 and does not show significant variation during the night. It should be noted, however, that the uncertainty in the retrieval of $m_{\mathrm{I}}$ is high (about $50 \%$ for $m_{\mathrm{I}}>0.005$ ), so any changes in $m_{\mathrm{I}}$ due to the uptake of water by the particles are beyond the sensitivity of the method and cannot be revealed.

\subsection{July measurements}

In contrast to 21 July the aerosol extinction on 22 July shows significant variation. As presented in Fig. 7, which shows particle extinction at $355 \mathrm{~nm}$ calculated by the Klett method using a lidar ratio of $70 \mathrm{sr}$, the top of the boundary layer drifts downward during the night from an elevation of $2.2 \mathrm{~km}$ to $1.7 \mathrm{~km}$. Between 03:30 UTC and 05:00 UTC a strong increase in extinction occurs, which is likely due to an intrusion of an external atmospheric layer. Figure 8 shows the spatio-temporal distribution of aerosol extinction at $355 \mathrm{~nm}$ calculated from the Raman nitrogen signal, retrieved volume density, effective radius, and the real part of the refractive index. On the color images for $r_{\text {eff }}$ and $m_{\mathrm{R}}$ the region with low particle extinction is removed (this region is marked in Fig. 8a with a solid line), because no reliable retrieval could be performed there. Again, as on 21 July, the variation of the volume density follows the particle extinction, while the effective radius is quite stable around a mean value of $r_{\text {eff }} \approx 0.24 \mu \mathrm{m}$. Note that the enhancement of the particle extinction after 03:30 UTC does not have a significant effect on the retrieved effective radius values. The value of $m_{\mathrm{R}}$ in-
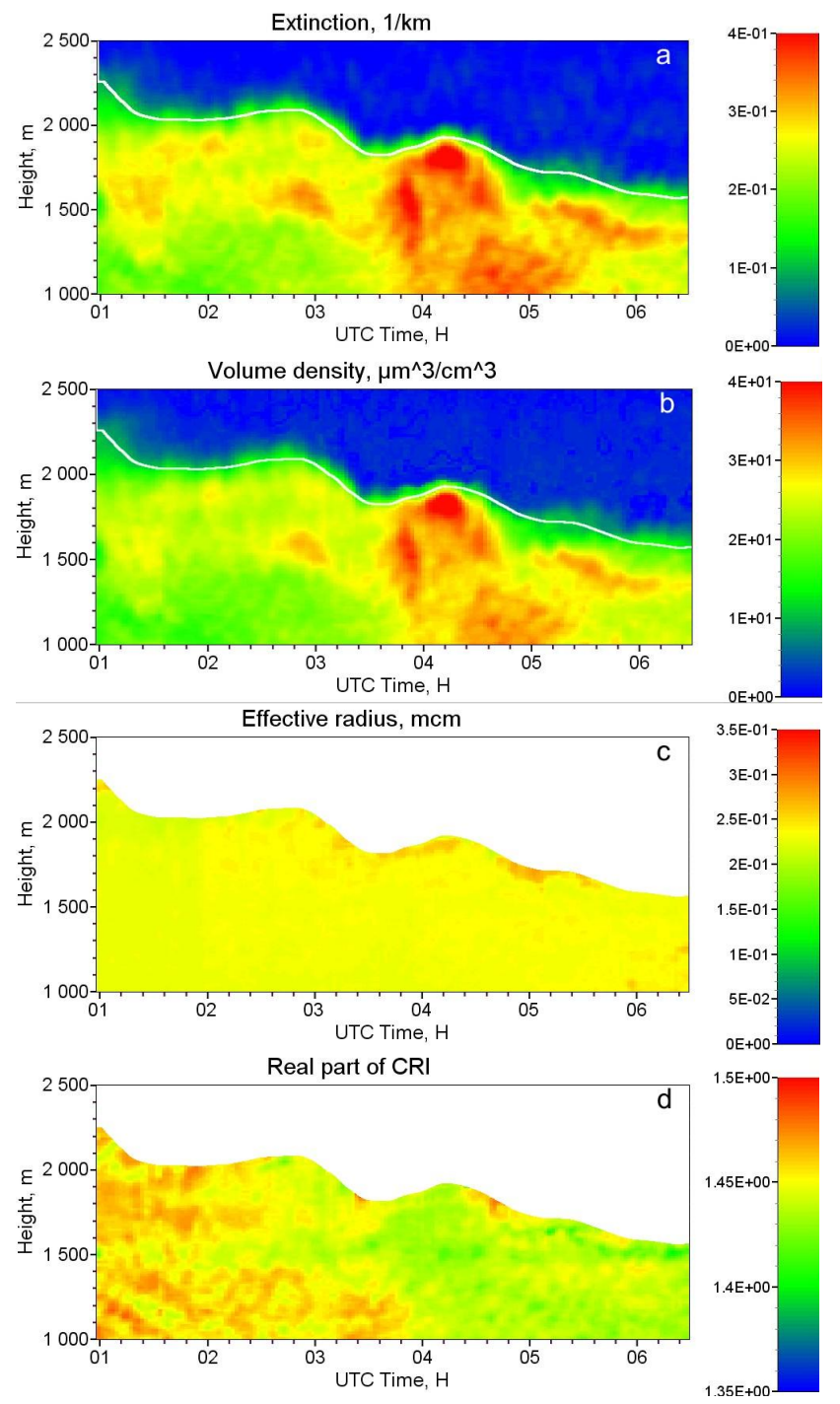

$1.5 \mathrm{E}+00$

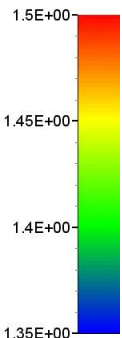

Fig. 8. Spatio-temporal distribution of (a) particle extinction at $355 \mathrm{~nm}$ calculated from the Raman nitrogen signal together with (b) particle volume, (c) effective radius and (d) the real part of the complex refractive index on 22 July 2011.

side the region with enhanced extinction (after 03:30 UTC) is lower, about 1.43 , while outside that region $m_{\mathrm{R}}$ is about 1.46 . To illustrate the variation of the particle parameters, Fig. 9 shows the time series of volume, number density, effective radius and $m_{\mathrm{R}}$ for two height layers centered at 1200 and $1600 \mathrm{~m}$ with thickness of $200 \mathrm{~m}$. The particle volume density rises with time in both layers, reaching a maximum value between 03:30 UTC and 05:00 UTC. This enhancement correlates with the rise of the particle number density. The effective radius rises slightly from 0.23 to $0.26 \mu \mathrm{m}$ during the night, while the real part of the refractive index in both layers decreases from 1.46 to 1.43 . The decrease in the value of $m_{\mathrm{R}}$ is likely due to water uptake by the particles. At the same time, simulation results presented in Fig. 3a demonstrate that 

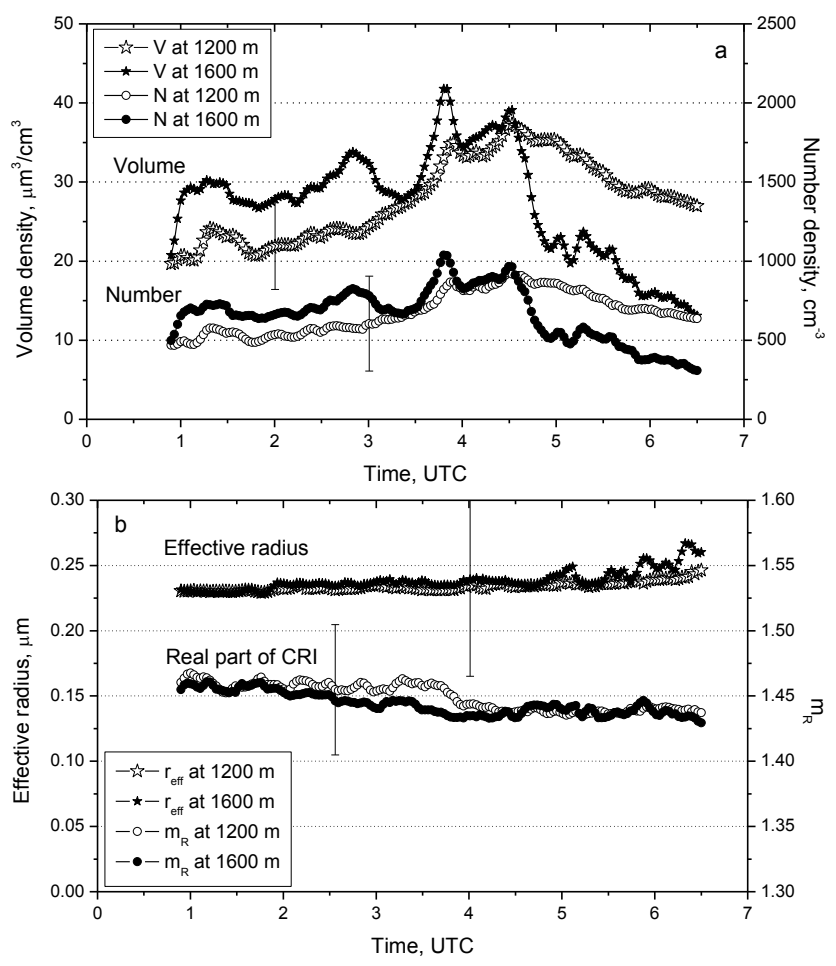

Fig. 9. Time series of (a) particle volume and number density together with (b) effective radius and the real part of the refractive index retrieved from the lidar measurements on 22 July 2011. The lidar-derived parameters are averaged in layers of $200 \mathrm{~m}$ thickness and centered at $1200 \mathrm{~m}$ (open symbols) and $1600 \mathrm{~m}$ (solid symbols) height.

the use of a reduced $3 \beta+1 \alpha$ data set may lead to a decrease of sensitivity to small particle sizes, which may explain the smoothness of the time series for the effective radius shown.

\subsection{Comparison of $L E$ and regularization retrievals}

All the retrievals presented above were obtained using a reduced $3 \beta+1 \alpha$ data set and the LE method. For an evaluation of such an approach it is important to compare the results of the LE and regularization algorithms when applied to both $3 \beta+2 \alpha$ and $3 \beta+1 \alpha$ data sets. The results of such comparison are given in this section. For this testing, we have chosen the measurements of 21 July. The calculated aerosol extinction and backscattering coefficients were averaged inside the 2000-2500 $\mathrm{m}$ height layer, and the retrieved particle properties are shown in Fig. 10. The volume densities obtained with the regularization and LE algorithms from both $3 \beta+2 \alpha$ and $3 \beta+1 \alpha$ data sets are similar. The inversion of the $3 \beta+2 \alpha$ data set with regularization leads to results that are generally consistent with the LE approach, but the retrieved volume density is characterized by higher scattering of the plot points. Removing $\alpha_{532}$ from the data set stabilizes the inversion with regularization, thus confirming the high sensitivity of the retrieval to errors in the extinction coefficient
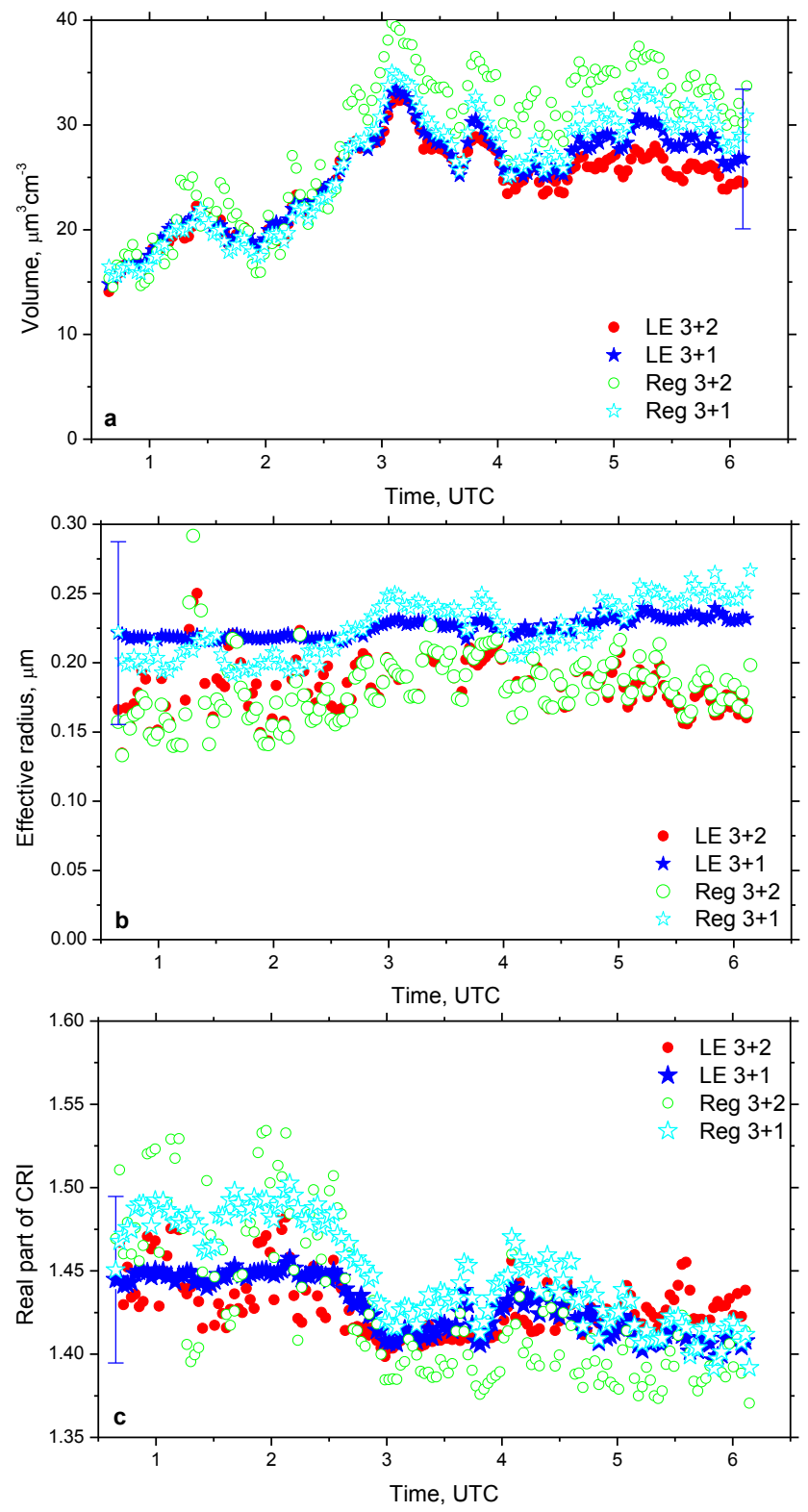

Fig. 10. Retrieval of (a) effective radius, (b) volume density and (c) the real part of CRI from measurements on the night of 2021 July 2011; the optical data are averaged in 2000-2500 m layer. Results are given for regularization and LE techniques applied to $3 \beta+2 \alpha$ and $3 \beta+1 \alpha$ measurements.

at $532 \mathrm{~nm}$. It demonstrates also that the LE approach is more tolerant to noise in the input data. The time series of effective radius obtained from $3 \beta+1 \alpha$ with LE is more stable compared to the same retrieval using $3 \beta+2 \alpha$, but $3 \beta+1 \alpha$ retrievals are shifted to higher values, which is in agreement with the simulation results for small particles in Fig. 3a. The results obtained with the regularization approach are consistent with LE.

The time series of the real part of CRI obtained with $3 \beta+$ $2 \alpha$ and $3 \beta+1 \alpha$ data sets are similar, but, again, including 


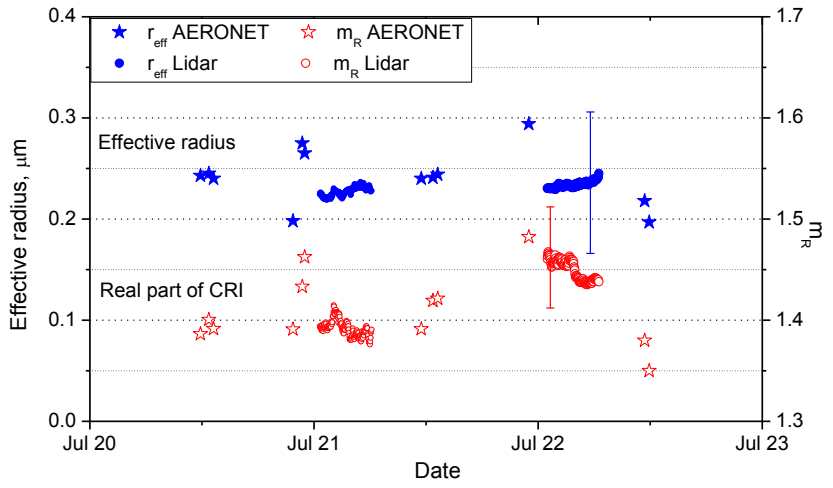

Fig. 11. Effective radius and the real part of the refractive index obtained from AERONET and lidar retrievals during the period of 20-23 July 2011. Lidar retrievals are given for the height layers at $1100 \mathrm{~m}$ (21 July) and $1200 \mathrm{~m}$ (22 July).

$\alpha_{532}$ leads to higher scattering of data points. The $m_{\mathrm{R}}$ retrieved with LE and regularization has similar behavior, but between 00:30 and 02:30 results obtained with regularizations are higher (1.48 comparing to 1.45); still this difference is inside the uncertainty of the method which we estimate as \pm 0.05 . Thus we can conclude that for all three particle parameters the difference between results obtained from the full and reduced data sets does not exceed the specified uncertainty of the method. Retrievals performed with LE and regularization are therefore consistent, but the LE algorithm operates more stably.

\section{Comparison with AERONET retrievals}

To evaluate the retrievals made here by use of the linear estimation technique, we compared the lidar-derived effective radius and complex refractive index with the results provided by AERONET (Dubovik and King, 2000). The lidar profiles are available only above $1000 \mathrm{~m}$ and AERONET retrievals are column averages; thus the two instruments are not measuring the same quantities. However, the backscattering profiles did not show significant variations below $1000 \mathrm{~m}$ and the retrievals above $1000 \mathrm{~m}$ also do not show large variations. Therefore, we believe that such validation is reasonable in the cases shown here. In our sessions, the first lidar sounding started approximately $1.5 \mathrm{~h}$ after the last AERONET measurement, so, given the generally stable conditions, we take the time gap to not be very significant.

Figure 11 shows the time series of effective radius and the real part of CRI obtained from AERONET and the lidar retrievals during the period of 20-23 July 2011. Lidar retrievals are given for the height layers at $1100 \mathrm{~m}$ (21 July) and $1200 \mathrm{~m}$ (22 July). Effective radius provided by AERONET presents significant scattering: for these days it varied between $0.2 \mu \mathrm{m}$ and $0.3 \mu \mathrm{m}$ with mean value $0.24 \mu \mathrm{m}$. The mean effective radius derived from the lidar measurements for 21 and 22 July is $0.23 \mu \mathrm{m}$. The real part of the refractive index retrieved by AERONET does not display a significant spectral dependence and, at $674 \mathrm{~nm}$, it varies between 1.35 and 1.49 during for 20-23 July period with a mean value 1.41 . The mean value of the real part obtained from the lidar measurements is 1.42. Thus, the retrievals from lidar and AERONET for both effective radius and the real part of the CRI are in reasonable agreement.

One of the main AERONET products is the columnintegrated particle volume. To get this same quantity from lidar measurements the volume density profile was extrapolated down to the ground, assuming that below a height of $1 \mathrm{~km}$ the volume density is constant. The lidar backscattering profiles do not indicate strong variation in the vertical so we do not expect this approximation to introduce large uncertainties. The column-integrated particle volume provided by AERONET at 23:00 UTC on 20 July is $0.109 \mu \mathrm{m}^{3} \mu \mathrm{m}^{-2}$ for the total PSD and $0.077 \mu \mathrm{m}^{3} \mu \mathrm{m}^{-2}$ when only the fine mode is considered. We present these two quantities as the lidar retrievals are known to be less sensitive to the coarse mode of the PSD (Veselovskii et al., 2004). The lidar-derived particle column volume during the night varied from $0.075 \mu \mathrm{m}^{3} \mu \mathrm{m}^{2}$ to $0.1 \mu \mathrm{m}^{3} \mu \mathrm{m}^{-2}$, which is below the AERONET value for the total PSD, but higher than the volume obtained for the fine mode only. Extrapolation of the lidar measurements to the ground can be a source of error, but still the agreement between lidar- and AERONET-derived values is reasonable. On 22 July, the top of the PBL was below $2 \mathrm{~km}$, so the relative contribution of the error due to extrapolation of the volume profile from $1 \mathrm{~km}$ to the ground could be large, and therefore the corresponding column-integrated volume was not considered.

We conclude that, though the comparison of AERONETand lidar-derived parameters cannot be considered as validation still lidar estimations of particle parameters are in reasonable agreement with those from AERONET.

\section{Discussion and conclusion}

We have presented the results of the application of the linear estimation technique to lidar measurements performed in July 2011 at NASA GSFC. The intention of this research was to show that multiwavelength lidars are able not only to provide vertical profiles of particle properties but also to reveal the spatio-temporal evolution of aerosol features. The desire to retrieve time series of particle parameters with high temporal resolution leads to the question of whether useful retrievals are possible with a reduced number of input data. The potential elimination from the input data set of the aerosol extinction calculated at $607 \mathrm{~nm}$ is attractive due to the significant averaging required in that measurement to reduce the statistical uncertainties to the desired $\sim 10 \%$. Also, recent sensitivity analyses (Perez-Ramirez et al., 2013) indicate that errors in extinction coefficients have the largest impact on 
retrieved particle properties, supporting the desire to exclude this measurement from the input data set if possible. The results of numerical simulations presented here indicate that, in fact, it is possible to exclude extinction at $607 \mathrm{~nm}$ from the input data while still providing a large amount of useful information about particle properties. The application of the LE algorithms to long-term $3 \beta+2 \alpha$ and $3 \beta+1 \alpha$ measurements demonstrates also that the results obtained are consistent at least for PSDs that are dominated by the fine mode.

Finally, $3 \beta+1 \alpha$ nighttime measurements acquired on 21 and 22 July were inverted to particle bulk properties with the LE algorithm. The results obtained confirm that the algorithm operates stably and that time series of particle parameters measured with 4 min resolution are provided without significant oscillations. We estimate the uncertainty of effective radius and the volume density retrieval as 30 and $25 \%$, respectively, whereas uncertainty for the retrieval of the real part of CRI is estimated to be \pm 0.05 . Estimation of the imaginary part of CRI is possible only if we have some initial idea of the range of $m_{\mathrm{I}}$ variation. Long-term AERONET measurements demonstrate that aerosols over GSFC are generally low-absorbing and that $m_{\mathrm{I}}$ generally is less than 0.015 , so this value can be used as a constraint under most conditions in the Greenbelt, MD area. For this situation $m_{\mathrm{I}}$ is estimated with an uncertainty of $50 \%$ in the range of $0.005-0.015$.

An important part of the evaluation of the LE approach is the comparison with AERONET, which today is considered as one of the most reliable sources of column particle parameters. The comparisons presented here show good agreement between the results obtained from the two instruments. Still, the comparisons performed cannot be considered as validation due to the different nature of the retrievals (column-oriented for AERONET and profiles for the lidar, where the profiles do not extend to the ground). Comparison of lidar measurements with AERONET and airborne in situ measurements should be performed at sites characterized by different types of particles and their mixtures for further investigation of the capabilities of these new retrieval methods. Also, spheroidal scattering models should be used when treating particles of irregular shape.

Finally, from the practical standpoint, our work shows that the linear estimation approach is computationally quite fast. For example, the inversion of an entire night of measurements takes approximately $10 \mathrm{~min}$ using a standard PC. The application of the LE and regularization techniques to the same data sets demonstrates also that LE is more tolerant to noise in input data. Thus, the LE technique used with multiwavelength HSRL or Raman systems has significant potential for air- and space-borne particle observations where data volumes can become quite large and where random uncertainties may be high.
Acknowledgements. We would like to acknowledge the AERONET team at NASA/Goddard Space Flight Center in Greenbelt, MD, for providing high-quality data and regular discussions of results.

Edited by: A. Kokhanovsky

\section{References}

Ansmann, A. and Müller, D.: Lidar and atmospheric aerosol particles, in: Lidar. Range-Resolved Optical Remote Sensing of the Atmosphere, edited by: Weitkamp, C., Springer, New York, 105141, 2005.

Ansmann, A., Riebesell, M., Wandinger, U., Weitkamp, C., Voss, E., Lahmann, W., and Michaelis, W.: Combined Raman elasticbackscatter lidar for vertical profiling of moisture, aerosols extinction, backscatter, and lidar ratio, Appl.Phys. B, 55, 18-28, 1992.

Böckmann, C., Miranova, I., Müller, D., Scheidenbach, L., and Nessler, R.: Microphysical aerosol parameters from multiwavelength lidar, J. Opt. Soc. Am. A, 22, 518-528, 2005.

Burton, S. P., Ferrare, R. A., Hostetler, C. A., Hair, J. W., Rogers, R. R., Obland, M. D., Butler, C. F., Cook, A. L., Harper, D. B., and Froyd, K. D.: Aerosol classification using airborne High Spectral Resolution Lidar measurements - methodology and examples, Atmos. Meas. Tech., 5, 73-98, doi:10.5194/amt-5-73-2012, 2012.

De Graaf, M., Donovan, D., and Apituley, A.: Feasibility study of integral property retrieval for tropospheric aerosol from Raman lidar data using principal component analysis, Appl. Opt., 52, 2173-2186, 2013.

Donovan, D. and Carswell, A.: Principal component analysis applied to multiwavelength lidar aerosol backscatter and extinction measurements, Appl. Opt., 36, 9406-9424, 1997.

Draxler, R. R. and Rolph, G. D.: HYSPLIT (HYbrid Single-Particle Lagrangian Integrated Trajectory) Model access via NOAA ARL READY website http://ready.arl.noaa.gov/HYSPLIT.php (last access: March 2013), NOAA Air Resources Laboratory, Silver Spring, MD, 2013.

Dubovik, O. and King, M. D.: A flexible inversion algorithm for retrieval of aerosol optical properties from Sun and sky radiance measurements, J. Geophys. Res., 105, 20673-20696, 2000.

Dubovik, O., Holben, B. N., Eck, T. F., Smirnov, A., Kaufman, Y. J., King, M. D., Tanré, D., and Slutsker, I.: Variability of absorption and optical properties of key aerosol types observed in worldwide locations, J. Atmos. Sci., 59, 590-608, 2002.

Dubovik, O., Sinyuk, A., Lapyonok, T., Holben, B. N., Mishenko, M., Yang, P., Eck, T. F., Volten, H., Munoz, O., Veihelmann, B., van der Zande, W. J., Leon, J.-F., Sorokin, M., and Slutsker, I.: Application of spheroid models to account for aerosol particle nonsphericity in remote sensing of desert dust, J. Geophys. Res., 111, D11208, doi:10.1029/2005JD006619, 2006.

Ganguly, D., Ginoux, P., Ramaswamy, V., Dubovik, O., Welton, J., Reid, E. A., and Holben, B. N.: Inferring the composition and concentration of aerosols by combining AERONET and MPLNET data: Comparison with other measurements and utilization to evaluate GCM output, J. Geophys. Res., 114, D16203, doi:10.1029/2009JD011895, 2009. 
Hair, J. W., Hostetler, C. A., Cook, A. L., Harper, D. B., Ferrare, R. A., Mack, T. L., Welch, W., Izquierdo, L. R., and Hovis, F. E.: Airborne High Spectral Resolution Lidar for profiling aerosol optical properties, Appl. Opt., 47, 6734-6752, 2008.

Holben, B. N., Eck, T. F., Slutsker, I., Tanre, D., Buis, J. P., Setzer, A., Vermote, E., Reagan, J. A., Kaufman, Y., Nakajima, T., Lavenu, F., Jankowiak, I., and Smirnov, A.: AERONET - a federated instrument network and data archive for aerosol characterization, Remote Sens. Environ., 66, 1-16, 1998.

Klett, J. D.: Lidar inversion with variable backscatter/extinction ratios, Appl. Opt. 24, 1638-1643, 1985.

Miller, D. J., Sun, K., Zondlo, M. A., Kanter, D., Dubovik, O., Welton, E. J., Winker, D. M., and Ginoux, P., Assessing boreal forest fire smoke aerosol impacts on U.S. air quality: A case study using multiple data sets, J. Geophys. Res., 116, D22209, doi:10.1029/2011JD016170, 2011.

Müller, D., Wandinger, U., and Ansmann, A.: Microphysical particle parameters from extinction and backscatter lidar data by inversion with regularization: theory, Appl. Opt., 38, 2346-2357, 1999.

Müller, D., Kolgotin, A., Mattis, I., Petzold, A., and Stohl, A.: Vertical profiles of microphysical particle properties derived from inversion with two-dimensional regularization of multiwavelength Raman lidar data: experiment, Appl. Opt. 50, 2069-2079, 2011.

Nishizawa, T., Sugimoto, N., Matsui, I., Shimizu, A., and Okamoto, H.: Algorithms to retrieve optical properties of three component aerosols from two-wavelength backscatter and one-wavelength polarization lidar measurements considering nonsphericity of dust, J. Quant. Spectrosc. Ra., 112, 254-267, 2011.

Noh, Y. M., Müller, D., Mattis, I., Lee, H., and Kim, Y. J.: Vertically resolved light-absorption characteristics and the influence of relative humidity on particle properties: multiwavelength Raman lidar observations of East Asian aerosol types over Korea, J. Geophys. Res. 116, D06206, doi:10.1029/2010JD014873, 2011.

Omar, A., Winker, D. M., Kittaka, C., Vaughan, M. A., Liu, Z., Hu, Y., Trepte, C. R., Rogers, R. R., Ferrare, R. A., Lee, K., Kuehn, R. E., and Hostetler, C. A.: The CALIPSO Automated aerosol classification and lidar ratio selection algorithm, J. Atmos. Ocean. Technol., 26, 1994-2014, 2009.

Pérez-Ramírez, D., Whiteman, D. N., Veselovskii, I., Kolgotin, A., Korenskiy, M., and Alados-Arboledas, L.: Effects of systematic and random errors on the retrieval of particle microphysical properties from multiwavelength lidar measurements using inversion with regularization, Atmos. Meas. Tech. Discuss., 6, 4607-4644, doi:10.5194/amtd-6-4607-2013, 2013.
Tesche, M., Ansmann, A., Müller, D., Althausen, D., Engelmann, R., Freudenthaler, V., and Gross, S.: Vertically resolved separation of dust and smoke over Cape Verde by using multiwavelength Raman and polarization lidar during SAMUM 2008, J. Geophys. Res., 114, D13202, doi:10.1029/2009JD011862, 2009.

Thomason, L. W. and Osborn, M. T.: Lidar conservation parameters derived from SAGE II extinction measurements, Geophys. Res. Lett., 19, 1655-1658, 1992.

Twomey, S.: Introduction to the Mathematics of Inversion in Remote Sensing and Linear Measurements, Elsevier, New York, 1977.

Veselovskii, I., Kolgotin, A., Griaznov, V., Müller, D., Wandinger, U., and Whiteman, D.: Inversion with regularization for the retrieval of tropospheric aerosol parameters from multi-wavelength lidar sounding, Appl. Opt., 41, 3685-3699, 2002.

Veselovskii, I., Kolgotin, A., Griaznov, V., Müller, D., Franke, K., and Whiteman, D. N.: Inversion of multi-wavelength Raman lidar data for retrieval of bimodal aerosol size distribution, Appl. Opt., 43, 1180-1195, 2004.

Veselovskii, I., Whiteman, D. N., Kolgotin, A., Andrews, E., and Korenskii, M.: Demonstration of aerosol property profiling by multi-wavelength lidar under varying relative humidity conditions, J. Atmos. Ocean. Technol. 26, 1543-1557, 2009.

Veselovskii, I., Dubovik, O., Kolgotin, A., Lapyonok, T., Di Girolamo, P., Summa, D., Whiteman, D. N., Mishchenko, M., and Tanré, D.: Application of randomly oriented spheroids for retrieval of dust particle parameters from multiwavelength lidar measurements, J. Geophys. Res., 115, D21203, doi:10.1029/2010JD014139, 2010.

Veselovskii, I., Dubovik, O., Kolgotin, A., Korenskiy, M., Whiteman, D. N., Allakhverdiev, K., and Huseyinoglu, F.: Linear estimation of particle bulk parameters from multi-wavelength lidar measurements, Atmos. Meas. Tech., 5, 1135-1145, doi:10.5194/amt-5-1135-2012, 2012.

Whiteman, D. N.: Application of statistical methods to the determination of slope in lidar data, Appl. Opt., 38, 3360-3369, 1999.

Winker, D. M., Tackett, J. L., Getzewich, B. J., Liu, Z., Vaughan, M. A., and Rogers, R. R.: The global 3-D distribution of tropospheric aerosols as characterized by CALIOP, Atmos. Chem. Phys., 13, 3345-3361, doi:10.5194/acp-13-3345-2013, 2013. 